\title{
All the way to the Altair and the fable of cowherd and the weaving maiden Ping Xu
}

\author{
Zaozhuang University, Zaozhuang Shandong, 277160 China
}

xupingdg@163.com

\begin{abstract}
Keywords: cowherd and weaving maiden; Altair and Vega; "All the way to the Altair"; deification; humanization; plebification;
\end{abstract}

\begin{abstract}
The fable of cowherd and the weaving maiden sprouted in the Pre-Qin period, and did not form a story with integrated plots until Han Dynasty. The poetry, "All the way to the Altair" ("Tiao Tiao Qian Niu Xing"), marks the most vivid description in the Han Dynasty. The evolvement of the fable of cowherd and the weaving maiden has undergone the processes of deification, humanization, and plebification. This poem, as one of the evidences of these processes, is influenced by folklore to reflect the objective reality with fables to show the poet's unique thinking on social life. Therefore, "All the way to the Altar" entails special value and charm.

The fable of cowherd and the weaving maiden, a household story, as one of the Four Ancient Chinese Legends, has been around for more than 2000 years. Throughout the ages, men of letters sang about the painful and beautiful story in literary works, arousing the emotional consonance of myriads of people, who always look up to the sky trying to find the constellations while listening to the beautiful tale.

The fable of cowherd and the weaving maiden sprouted in the Pre-Qin period, and basically forms a story with integrated plots in Han Dynasty. However, its evolvement has undergone a long period of history. The fable originates from the primitive belief of star worship. Because of the low productive forces, the people of that time were at the mercy of the forces of nature, confused about all kinds of natural phenomena. And thus intense awe and worship towards the great universe were generated. Naturally, those macroscopic and seemingly eternal stars are worshipped by the mass. In the ancient astronomical map, Altair, also known as Constellation of Ox, is one of the 28 Constellations and ranks second in the Seven Northern Tortoise-Snake Constellations. The Vega, also known as Tiansun, lies in the west side of the Milky Way, facing the Altair in the east side at a distance.

As early as three thousand years ago, people at that time noticed the unique position of the Altair and Vega which spurred some association with the real life. The earliest written records should be "The Book of Songs . Xiao Ya . Da Dong", chanting "Look at the Milky Way in the sky. The twinkling stars splendidly shine. The weaving girl stars in triangle way, keep on shuttling seven times a day. Although coming over and passing by, they can't weave nice coats of arms. Though the Altair stars brightly shine, they are not able to drive our carts. " It well manifests that our ancestors have linked the heaven with the earth, applying the commonplace phenomenon to the relationship between those two constellations, adding an earthly flavor to the natural phenomenon. Therefore, although Altair and Vega are still constellations in the sky, their descriptions are somewhat linked with reality, rather than being purely objective.

The weaver girl, originally the name of a constellation, has evolved into that of a goddess in the later literature Chunqiu Yuanmingbao and Huainanzi. It is stated in Bangu's Ode to the Two Capitals, the statue of the Cowherd is placed in the left side of Kunming Pool and the weaver girl in the right . The wide range of the river resembles the boundlessness of the milky way; Li Shan in the note cited in The Imperial Palace of the Han Dynasty says that "there are two statues at the two sides of the Kunming Pool, namely 'the cowherd' and 'the weaver girl,'. These show that in Han dynasty, the images of the cowherd and the weaver girl have been transformed from two constellations into two gods, more importantly, one is male and the other is female. Although the relationship of the two has not been elaborated, they are always connected. Besides, the image of their silently gazing at each other at the two sides of the Kunming Pool, naturally, will arouse people's imagination . Therefore, Taiwan scholar Wang Xiaolian thinks that in Ode to the Two Capitals, the cowherd and the weaver
\end{abstract}


girl have been personified, and hence he infers that their personification comes into being during the Western Han Dynasty with the Emperor Wu of Han and the Eastern Han Dynasty with the Emperor Ming of Han.

Moreover, it is clearly dcumented in Huainanzi that the magpies will get together and form a bridge in the milky way in order to let the weaver girl reunite with the cowherd in the other side; Cui Shi of the Eastern Han Dynasty says in his Monthly Instructions for Four Classes of People that "two gods---the cowherd and the weaver girl will meet each other on the 7th day of the 7th lunar month", which means that in t people's imagination at that time, the two are not just close As a matter of fact, they are lovers. According to Wu dezhu's Portrait Stone of the Han Dynasty, in Xiaotang Mountain Han Shrine (located at Xiaotangshan, Xiaolipu, Licheng County, Shandong Province), there is a piece of stone star atlas in which the Altair and the Vega are at the very two sides, and below the Vega is a girl who is weaving with a bird flying nearby. And Ying Shao in the Eastern Han Dynasty in his Development and Evolution of Customs says that on the lunar July 7th, the weaver girl will cross the milk river through the bridge formed by the magpies and that's why the they will lose feathers on their heads on that day. Thus, it can be inferred that the legend of the cowherd and the weaver girl has been widely spread in public in the Han Dynasty. And the main frame of the story, to be concrete, firstly they are a couple of lovers, secondly they are kept away from each other by the milky river, and lastly they can only meet on the lunar July $7^{\text {th }}$ with the help of the magpies has been formed. It is because of their vivid love story that the two are no longer two distant constellations, or two gods, but a couple of lovers with fresh and bones, and full of human emotions. Through fantasy and bold imagination, the weaver girl and the cowherd have been successfully transformed from constellation to god and finally to human beings. They are becoming more and more closed with people. And hence the images of the two constellations have no longer been mysterious, vague and remote, but instead friendly, life-like and vivid.

To the end of Eastern Han dynasty, the Poem "The Two Silently Watch Each Other", included in "Nineteen Old poems", has been the only one that finely tells the story of the Cowherd and the Girl Weaver in a literary way. The poem goes that"Far, far away, the Herd-lad, Fair, fair, the weaving-maid.Deft white hands are weaving, Click, click, the loom moving. She is weaving all day long, Yet can't get the cloth done.Like rain, her tears well down. Clear and shallow the milky way,

When is the lovers' meeting day? So wide is the stream here, They can gaze at each other,But cannot speak and hear!"

Although this is a Yongwu poem, the stars are personified. So people can see a beautiful and sensible girl Waver who is also clever in mind and skillful in hand. She is tortured by the separation with the Cowherd and has got lovesickness, but it is impossible for her to break through the restraint of the Milky Way, so she has to grin and bear it. The sentence "She is weaving all day long, yet can't get the cloth done. Like rain, her tears well down." is the implicit interpretation of strong pain in the girl Waver's heart. The poem is the most impressive description of the Cowherd and the Girl Weaver in Han Dynasty, which has been very infectious for thousands of years.

"Nineteen Old poems" plays an important role in the course of Chinese poetry, which is a sign of the mature of literati poetry and has a deeply influence to the development of later poems. The author of the "Nineteen Old poems" is not only one person and not been written in the same time or place. But as the refined scholars from the lower middle class, they have similar experience and inspirations. So their poems are similar in content and style. In "Nineteen Old poems", the poets usually express their complex and subtle emotions by poems, such as "Northwest has a Tall Building" and "Drove on the East Gate" etc. And it is rare to see a Yongwu poem like "The Two Silently Watch Each Other". So why does the poet write such a poem? Is it a poem just for describing an object?

Although the poem can prove that story of the Cowherd and the Girl Weaver has been basically formed and widespread, this is definitely not the reason why the poet writes it. This poem focuses on the expression of feelings, not description of objects. It takes advantage of this tragic love story to express his emotions and reflection to the real life.

By the end of the Han Dynasty, the nineteen ancient poems, with social chaos and hard life, appears in the gradually turbulent times. In order to make a living, people, who live in middle or 
lower class, often leave their hometown and wander. They are in a circumstance as follows: away from home and loved ones; in the fickleness of human nature and the world; in the pain of the lovesickness and loneliness; maybe even die in a strange land in a penniless dilemma without the accompany of any relatives. In the crumbling of the moment, the true feelings of the ordinary people are more precious and touching, gradually arousing the attention of the people. "People" will gradually become a literary theme when people began to awaken examine and think as well as when the individual life becomes special and significant in troubled times. Thus, to cherish think and enjoy life as well as paying attention to love become one of the significant parts of ancient poetry. Travers and lovesick women as the protagonist appear frequently in the poems, such as The Long Walk, Guests from afar, The Cold Cloud Twilight Years, Slowly Solitary Bamboos, showing the people of sadness and helplessness. These poems are on the true and deep reflection of objective reality, which shows that literati, at that time, emphasize one of the important parts of human emotion-love- it is ignored before but now as the theme of recognition and praise by scholars. Thus, it is profound and practical to personate the double stars as an affectionate but separate couple.

In addition, the author portrays the Weaver as a good-weaving woman who has the figure of personification and civilian. She is no longer a noble but an ordinary woman, not a superior goddess but a clever citizen. In ancient China, men tilling in the farm and women weaving in the home is a common way of life, so that use this image to describe the Weaver is full of national features. Mr. Wang Xiaolian, in the book Chinese myth in the world, points out: "the legend of the Cowherd and the Weaver is never simply a story of astronomy but the tales of legend, which combine the worship of farming belief and astronomical observation of an actual astrology. That is to say the Legend of the Cowherd and the Weaver is never simply created by the ancient observation of astronomical phenomena and imagination, but conformed on earth as the background combining with astronomical phenomena in real life." Therefore, the legend of is actually a combination of farming civilization and astronomical worship. In Han Dynasty, agricultural economy makes further development, from top to bottom attaching great importance to the status and role of agriculture in the country as a whole, which inevitably affects the formation and spread of the legend and naturally cause attention of the poets.

In addition, the social reality at the end of the Han Dynasty may also touch the poet's thoughts. Although the poet was not sure his own misfortune love, but he would certainly be able to witness some love tragedy. In that society full of sufferings, homesick women and tramps got together hardly with each other, and lovers were forced to separate and even part forever. Not only reflects the "Nineteen Ancient Poems", but other literary works also show this content. For example, the love tragedy of "Peacock Flying Southeast", a poetic masterpiece through the ages, is still heart-shaking after more than one thousand years. In the "Long Altair", the author not only depicted the inner pain and sadness of the weaver with exquisite brushwork, but delicately hinted the reasons why they could not be free to stay together: " The Milky way is clear and shallow, how far is it apart? Although from the distance of a clear and shallow river, they could not talk to each other with full of tender affection." This shows that the couple is neither like " living apart from you, from now on you and me apart from thousands of miles" ("Keep walking"), nor" prodigal son not return traveling alone, an empty bed difficult to be lonely. "(" Green River grass"), but they had to separate due to the unspeakably man-made causes, though very close, very much in love, so that they must silently bear all the pain. Although this poem did not reveal the love tragedy and its causes of Jiao Zhongqing and Liu Lanzhi, protagonists of "Peacock Flying Southeast" with concrete and vivid means as "Peacock Flying Southeast", its euphemistic and implicit styles did leave immerse impressions to readers extremely. The author endowed to a lifeless binary star with beautiful and sad love, painful and helpless psychology, which, in fact, is portrayals of countless ordinarily unfortunate couples in the boundless universe so that it can still makes readers have a strong resonance after thousands of years.

While the eternity of double star and the vastness of the university contrast to the weakness of the individuals and the helplessness of life. Double star exists forever, shining all the time, however, people's life is short and limited. The weak and humble ordinary people can only helplessly admire the distant stars, filled with sadness and loss. So this poem not only intones the love but also reveals 
the consciousness of the life, which shows the concern and investigation about life, life issues and human by the literati in the late Han Dynasty. Compare with it, they live less than a hundred years, while worry more than a thousand years"(Live less than a hundred years), and "life likes the sojourn which remains the dust in a century, but would be blew by the gale suddenly"(Today's feast) have achieved the same result by different methods.

In conclusion, The faraway Altair was deeply influenced by the well-known legend of Niulang and Zhinv at that time, which also described and expressed the emotions by using the particular form of the poetry. And it has become the most vivid and complete description since the Han Dynasty. At the meanwhile, the author reflected the reality truly and objectively. He not only used the legend's construction to express the life and emotions of common people, but also mixed the philosophic consideration of the society as a sensitive literati, which made the poem full of monumental charm. According to this poem, the evolution's track of the Niulang and Zhinv's story can be seen, which means the process of deifying, humanizing and popularizing the double star. The popularization of double star brings people closeness and warm instead of distance and cold, becoming the specific reflection of the real world. The mode of legends shows the life and emotions of the society, which cements the foundation for polishing and vivifying the legend of Niulang and Zhinv in the future.

\section{References}

[1] Liu Xiaohong. The evolution of Legend of the Cowherd and the Girl Weaver [J]. Journal of Xuzhou Education College, Vol.18,No.4.

[2] Hu Anlian. The evolution and its cultural meaning of Legend of the Cowherd and the Girl Weaver [J]. Journal of Xuchang Teachers College No.1,2001.

[3] Zhang Zhenlong. Nineteen Ancient Poems and the emotional world of scholars in the late Han Dynasty [J]. Yindu Journal No.2,2000.

[4] Li Li. The interpretation of the secularization of Legend of the Cowherd and the Girl Weaver in the Han Dynasty [J]. Journal of Luoyang Teachers College, Vol.18,No.1.

[5] Wang Yaqing. On the evolution of the theme of the story of the Cowherd and the Girl Weaver [J]. Journal of Yuxi Teachers College No.5,1994. 